\title{
Posttreatment of Upflow Anaerobic Sludge Blanket-Treated Industrial Wastewater by a Rotating Biological Contactor
}

\author{
Ayoob Torkian, S. J. Hashemian, and K. Alinejad
}

\begin{abstract}
The performance of a rotating biological contactor (RBC) for posttreatment of the slaughterhouse effluent from an upflow anaerobic sludge blanket (UASB) reactor was investigated in this study. The $280-\mathrm{L}$ (by volume), six-stage RBC pilot plant was operated at different organic loading rates (OLRs) and biodisk speeds. The overall removal efficiencies for soluble chemical oxygen demand (SBOD), total biochemical oxygen demand (TBOD), and total chemical oxygen demand (TCOD) decreased with increasing OLRs. Disk rotational speed did not have a significant effect on performance in the range studied.

The results showed that satisfactory posttreatment to meet regulatory requirements for agricultural purposes (effluent biochemical oxygen demand of $100 \mathrm{mg} / \mathrm{L}$ ) can be achieved at an OLR of $5.3 \pm 2.9 \mathrm{~g}$ SBOD $\cdot \mathrm{m}^{-2} \cdot \mathrm{d}^{-1}$, with an SBOD removal efficiency of $85 \pm 3 \%$. Most of the organics were removed during the first three stages, with minimal contribution from the remaining stages of the RBC reactor. There was a decrease in SBOD removal efficiency to $74 \pm 3 \%$ at an OLR value of $17.8 \pm 2.1 \mathrm{~g} \mathrm{SBOD} \cdot \mathrm{m}^{-2} \cdot \mathrm{d}^{-1}$.

The results for elimination capacity indicated a linear relationship with first-stage OLRs without any signs of limitation at the range of loading rates investigated in this study. However, average first-stage elimination capacity rates of 4.8 and $3.8 \mathrm{~g} \cdot \mathrm{m}^{-2} \cdot \mathrm{d}^{-1}$ of 17.8 and $11 \mathrm{~g} \mathrm{SBOD} \cdot \mathrm{m}^{-2} \cdot \mathrm{d}^{-1}$ were relatively lower than previous studies of RBC performance using domestic or industrial wastewater without anaerobic pretreatment. It was suggested that the lower elimination capacity rates were due to the fact that a smaller fraction of UASB effluent was biodegradable as reflected in TBOD/TCOD ratios of $0.47 \pm 0.04$. Water Environ. Res., 75, 000 (2003).
\end{abstract}

KEYWORDS: rotating biological contactor, biofilm, fixed-film treatment, upflow anaerobic sludge blanket process, slaughterhouse effluent, industrial wastewater.

\section{Introduction}

The environmental impact of slaughterhouse effluent has grown because of increased plant production. High concentrations of biodegradable organic matter renders aerobic treatment inefficient because of high energy requirements for aeration, limitations in liquid-phase oxygen transfer rates, and high sludge production. Traditional anaerobic processes are also limited by low rates of organic matter removal, long hydraulic residence times (HRTs), accumulation of excessive residual organic matter and intermediate products, and large reactor volume requirements. Recent developments in anaerobic treatment processes, especially high retention of biomass in the reactor, has made the decoupling of solids retention time and HRT in the high-rate anaerobic reactors possible. The upflow anaerobic sludge blanket (UASB) process is one of these systems. It has been widely adopted for treating medium- to highstrength industrial wastewaters (Fang et al., 1995; Lettinga and Hulshoff Pol, 1991). However, UASB effluent has to be complemented by suspended- or fixed-growth aerobic posttreatment to meet applicable discharge standards for surface water or irrigation purposes.

A rotating biological contactor ( $\mathrm{RBC}$ ) process is an efficient and reliable posttreatment system for anaerobically pretreated wastewater. It is a fixed-growth aerobic treatment system consisting of a series of biomass-covered hard plastic disks partially submerged in wastewater and in alternate contact with wastewater and exposure to air. Needed nutrients for microbial community are derived from the wastewater film flowing over the surface of the disks, and oxygen is supplied from air. Although different configurations can be used, the multistage concept has proven more efficient. Since its first application in Europe in the late 1950s and early 1960s, a growing market has been reported for both domestic and industrial effluents ranging from small units serving residential dwellings to large ones treating large flows of up to several million liters (Banerjee, 1997; Borghi et al., 1985; Saggy and Kott, 1990; Strom and Chung, 1985). The principal reasons are easy construction, simplicity of operation and maintenance, stability under shock loads, and low energy consumption. Modifications made to augment performance characteristics of RBCs have made these units more popular in the past two decades.

Different operational parameters influencing reactor performance including rotational speed of disks (Friedman et al., 1979), dissolved oxygen (DO) concentration of wastewater (Paolini, 1986), organic and hydraulic loading (Lin et al., 1986), and number of stages (Andreadakis, 1987; Evans, 1985) have been studied to elucidate the behavior and thus the performance of the RBC process. Fixed-film biomass accounts for almost all of the activity observed, and the role of suspended growth is minimal and significant only for enhancing biofilm development on the disk media (Ware and Pescod, 1989). Tyagi et al. (1993) reported up to $88 \%$ removal efficiency of total chemical oxygen demand (TCOD) from petroleum refinery effluent at a disk speed of 10 $\mathrm{rpm}$ and various hydraulic loading rates (HLRs) (0.01 to 0.04 $\left.\mathrm{m}^{3} \cdot \mathrm{m}^{-2} \cdot \mathrm{d}^{-1}\right)$. At an organic loading rate (OLR) of $7.8 \mathrm{~g}$ soluble biochemical oxygen demand (SBOD) $\cdot \mathrm{m}^{-2} \cdot \mathrm{d}^{-1}$, Poon et al. (1981) did not observe a significant effect from disk speed variations in the 3 to $7 \mathrm{rpm}$ range. Results from RBC treatment of slaughterhouse effluent (Blanc and Corr, 1983) showed a maximum of $74 \%$ chemical oxygen demand (COD) removal at an OLR of $5 \mathrm{~g}$ SBOD $\cdot \mathrm{m}^{-2} \cdot \mathrm{d}^{-1}$.

In this study, the feasibility of using an RBC for posttreatment of effluent from UASB effluent was studied. Particular attention was paid to system stability under different OLRs and disk speeds. The results for performance of different stages are also presented. 


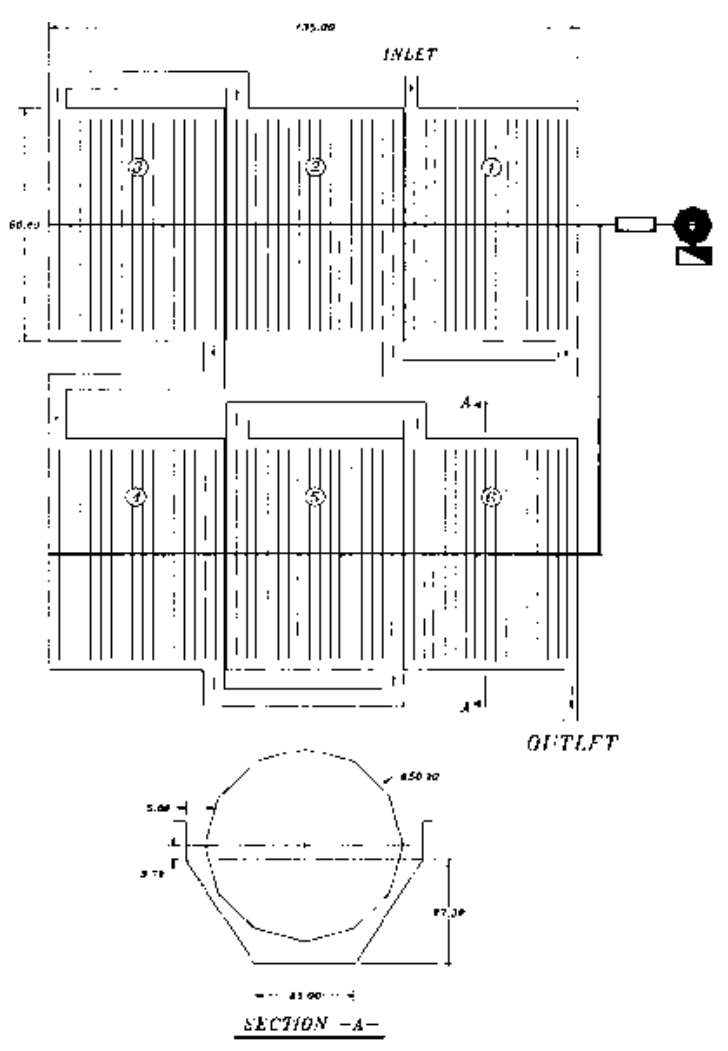

Figure 1-Schematic diagram of the RBC.

\section{Materials and Methods}

Experimental Setup. A six-stage RBC system was set up downstream of a UASB reactor. The $280-\mathrm{L}$ working volume pilot plant used in this study (Figure 1) contained 16 hard polyethylene disks with an effective surface area of $0.375 \mathrm{~m}^{2}$. The diameter of the disks was $0.5 \mathrm{~m}$ with a thickness of $0.03 \mathrm{~m}$, and the disks were spaced at $0.03-\mathrm{m}$ intervals. The disks were $37 \%$ submerged into wastewater. The system was covered to retard photosynthetic growth.

Feed. The wastewater stream from the traditional slaughterhouse used as influent to the UASB reactor consisted of effluent from a combination of several stages including blood from slaughtering operations, wash waters from stomach and intestines, and wastewater from refrigerated chambers and toilets. There was no differentiation of effluent from these operations and, because of the inherent nature of the process, characteristics varied at different times. Addition of nutrients was not deemed necessary because wastewater characteristics including lack of blood recovery indicated adequate concentration of essential proteins and trace elements.

Characteristics of RBC influent were dependent on UASB reactor performance, which was, in turn, a function of slaughterhouse operations. A sedimentation tank was used to capture high solids content of influent at times of UASB malfunction and sludge washout. The interval and average values of different parameters are shown in Table 1. The DO concentration was less than 0.5 $\mathrm{mg} / \mathrm{L}$ most of the time because no auxiliary aeration was provided prior to RBC entry. The characteristic "rotten egg" smell of hydrogen sulfide was noticeable leading up to the growth of sulfur bacteria on the first few disks of the first stage. Furthermore, the
Table 1-Wastewater characteristics of RBC influent at different periods of study.

\begin{tabular}{lcc}
\hline Parameter & Range & Average \\
\hline SBOD (mg/L) & $331-1160$ & $624 \pm 264$ \\
TBOD (mg/L) & $658-1460$ & $961 \pm 257$ \\
SCOD (mg/L) & $721-2273$ & $1122 \pm 433$ \\
TCOD (mg/L) & $1415-3426$ & $2061 \pm 637$ \\
SBOD/SCOD ratio & $0.43-0.85$ & $0.55 \pm 0.09$ \\
Total suspended solids (mg/L) & $400-1498$ & $729 \pm 305$ \\
Volatile suspended solids (mg/L) & $243-1099$ & $729 \pm 305$ \\
Ammonium nitrogen (mg/L) & $26-46$ & $36 \pm 15$ \\
Total kjeldahl nitrogen (mg/L) & $36-64$ & $52 \pm 15$ \\
Soluble phosphorus (mg/L) & $3.2-5.6$ & $3.9 \pm 1.6$ \\
pH & $7.1-7.8$ & $7.5 \pm 0.2$ \\
\hline
\end{tabular}

fraction of biodegradable organics was different from the raw wastewater in that the UASB reactor treated the majority of these constituents.

Operation. The UASB reactor contained granulated sludge formed previously in the reactor. Slaughterhouse effluent was pumped into a reservoir from the main slaughterhouse sewer containing composite effluent from different units. After separating inert particles in a cyclonic grit chamber, effluent was pumped into a container at the top and then fed by gravity into the influent distribution line of the reactor. Although it was possible to direct flow into the different stages of the RBC reactor in parallel, series, or a combination of both, in this study only the series option was used. Samples were collected two to three times a week from the influent and stages 1,3 , and 6 .

Two operating schemes were selected. During the first three phases of the study, disk speed was set at $8 \mathrm{rpm}$ and organic load was varied; during the next three phases, disk speed was set at 11 rpm. Variation of organic load was achieved by a combination of the use of different influent concentrations to the UASB reactor and, to a lesser extent, hydraulic load variation to the $\mathrm{RBC}$ reactor. The HLR to the RBC reactor was less varied to avoid complications in data analyses resulting from the concurrent change of both OLR and HRT. Influent concentrations to the UASB reactor were varied by filling the feed reservoir, which was filled once a day, at different times of the day. The temperature of the wastewater was different for different disk speeds mainly because the reactor temperature was governed by temporal variations and no temperature compensation mechanism was in place. Other operating conditions and performance indicators are presented in Table 2.

Analytical Methods. Grab samples of influent as well as effluent from stages 1,3 , and 6 of the reactor were collected in containers, stored in a refrigerator at $4{ }^{\circ} \mathrm{C}$, and analyzed within 24 hours of collection. Routine analyses including soluble (filtered sample with a $0.45-\mu \mathrm{m}$ pore size glass microfiber filter) total 5 -day biochemical oxygen demand (BOD), COD, nitrogen, and phosphorus were performed using procedures outlined in Standard Methods (APHA et al., 1985).

Experimental Design. Operational and Performance Parameters. Operational and performance parameters include OLR, HLR, removal efficiency ( $\eta$ ), elimination capacity (EC), and HRT. Loading rates can be studied in terms of the pollution indicator, empty reactor bed volume, disk surface area, and microbial mass. The OLR used here takes into account the liquid flowrate and 
Table 2-Summary of operating conditions for the RBC reactor.

\begin{tabular}{|c|c|c|c|c|c|c|c|c|}
\hline Phase & Period (d) & $\begin{array}{c}\text { HLR } \\
\left(\mathrm{m}^{3} \cdot \mathrm{m}^{-2} \cdot \mathrm{d}^{-1}\right)^{\mathrm{a}}\end{array}$ & HRT $(h)^{a}$ & $\mathrm{~T}\left({ }^{\circ} \mathrm{C}\right)^{\mathrm{a}}$ & $\begin{array}{c}\text { Disk } \\
\text { speed (rpm) }\end{array}$ & $\begin{array}{l}\text { SBOD } \\
(\mathrm{mg} / \mathrm{L})^{\mathrm{a}}\end{array}$ & $\begin{array}{l}\text { SCOD } \\
(\mathrm{mg} / \mathrm{L})^{\mathrm{a}}\end{array}$ & $\begin{array}{c}\text { OLR } \\
\left(\mathrm{mg} \mathrm{SBOD} \cdot \mathrm{m}^{-2} \cdot \mathrm{d}^{-1}\right)^{\mathrm{a}}\end{array}$ \\
\hline 1 & $1-22$ & $0.013 \pm 0.002$ & $16.0 \pm 3.9$ & $17.1 \pm 3.7$ & 8 & $987 \pm 115$ & $1860 \pm 322$ & $17.8 \pm 2.1$ \\
\hline 2 & $23-60$ & $0.013 \pm 0.002$ & $16.0 \pm 3.9$ & $17.1 \pm 3.7$ & 8 & $887 \pm 201$ & $1315 \pm 285$ & $8.9 \pm 2$ \\
\hline 3 & $61-85$ & $0.013 \pm 0.002$ & $16.0 \pm 3.9$ & $17.1 \pm 3.7$ & 8 & $525 \pm 286$ & $918 \pm 233$ & $5.3 \pm 2.9$ \\
\hline 4 & $85-114$ & $0.017 \pm 0.006$ & $13.3 \pm 4.3$ & $30.0 \pm 1.7$ & 11 & $432 \pm 31$ & $898 \pm 96$ & $11 \pm 2.9$ \\
\hline 5 & $114-128$ & $0.017 \pm 0.006$ & $13.3 \pm 4.3$ & $30.0 \pm 1.7$ & 11 & $483 \pm 25$ & $849 \pm 82$ & $7.3 \pm 0.4$ \\
\hline 6 & $128-143$ & $0.017 \pm 0.006$ & $13.3 \pm 4.3$ & $30.0 \pm 1.7$ & 11 & $488 \pm 36$ & $875 \pm 55$ & $4.9 \pm 0.4$ \\
\hline
\end{tabular}

a \pm Standard deviation.

contaminant concentration and is defined as the mass of pollutant applied to a unit area of RBC reactor disk area per unit time (e.g., grams of COD per square meter of disk per day). As such, this parameter integrates reactor characteristics, operating characteristics, and biofilm mass and activity into the surface area of the biodisks. The HLR is a measure of the amount of time a given parcel of liquid is "seen" by a unit disk surface area (e.g., cubic meter of wastewater per square meter of disk per day). This parameter is more indicative of the effective time for mass transfer of pollutants to the biomass than HRT because the majority of biodegradation takes place by the biofilm attached on the disks.

Elimination capacity can be used as a performance indicator. The elimination capacity is related to the OLR in that it is defined as the fraction of the organic load that is biodegraded (e.g., grams of COD per square meter of disk per day). The elimination capacity differs from removal efficiency, which is an operational parameter that is a measure of the effectiveness of the reactor in degrading a contaminant. Elimination capacity is a useful parameter for design purposes, and removal efficiency, (e.g., percent) helps an operator determine if the system is complying with regulatory effluent requirements.

Hydraulic residence time is the time (e.g., hours) the contaminant spends in the effective volume of the $\mathrm{RBC}$ reactor. This volume may be less than the total reactor volume because of the empty spaces at the inlet, outlet, and sludge collection zone or the volume occupied by biodiscs.

The mass (organic) loading rate, elimination capacity, HLR, HRT, and removal efficiency were determined using the
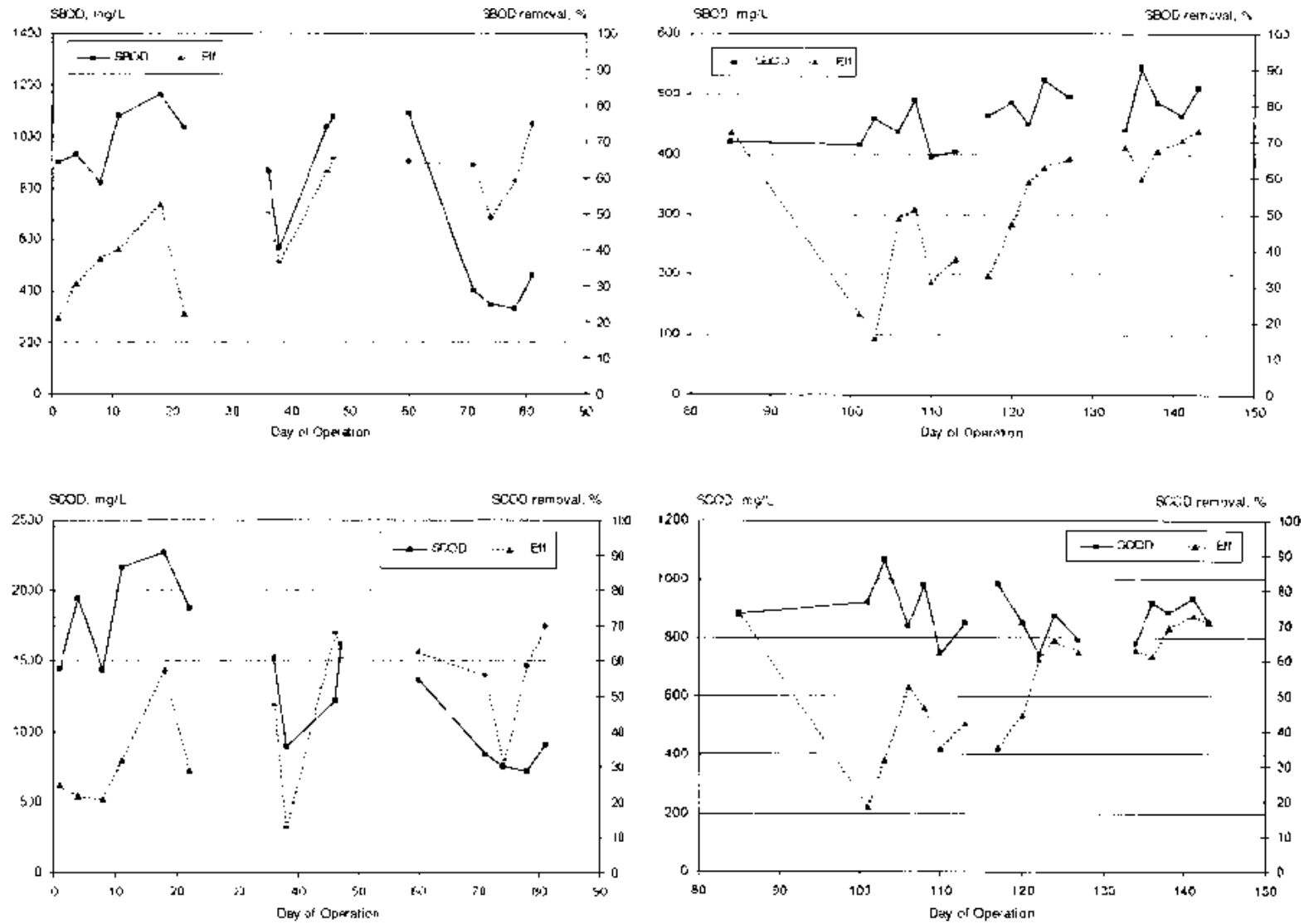

Figure 2-Overall removal efficiencies at different OLRs. 


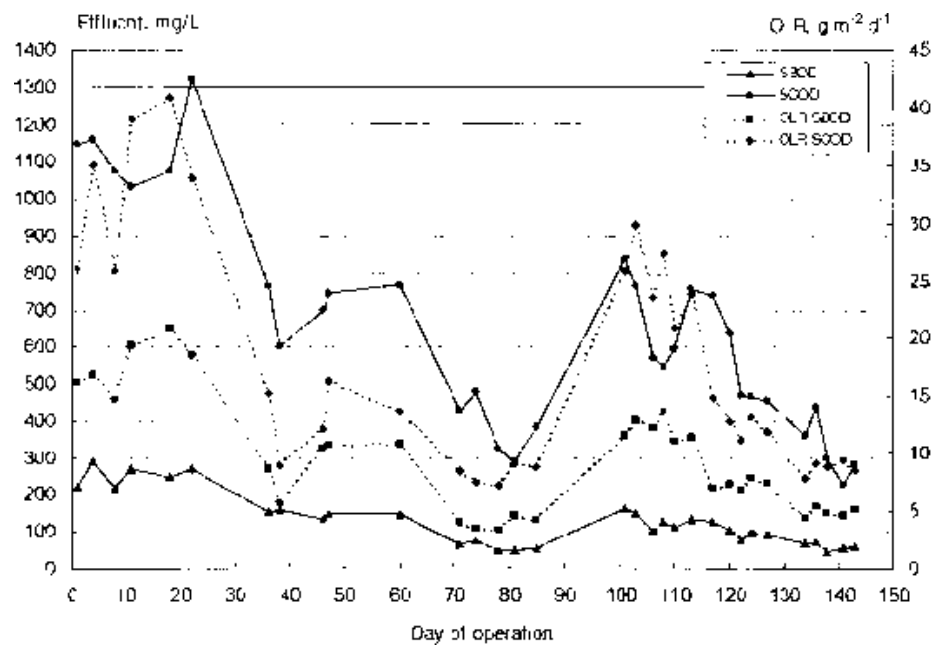

Figure 3-Effluent concentration of the RBC reactor at different OLRs.

relationships between influent and effluent contaminant concentrations, effluent flowrate, the effective volume of the RBC reactor, and by applying the appropriate conversion factors, as follows:

$$
\begin{aligned}
\mathrm{HRT} & =\frac{V_{r}}{Q} \\
\mathrm{HLR} & =\frac{Q}{A_{d}} \\
\mathrm{OLR} & =\left(\frac{Q}{A_{d}}\right) C_{\mathrm{in}} \\
\mathrm{EC} & =\left(\frac{Q}{A_{d}}\right)\left(C_{\mathrm{in}}-C_{\mathrm{out}}\right) \\
\eta & =\left(\frac{C_{\mathrm{in}}-C_{\mathrm{out}}}{C_{\text {in }}}\right) 100
\end{aligned}
$$

Where:

$$
\begin{aligned}
Q & =\text { effluent flowrate }\left(\mathrm{m}^{3} \cdot \mathrm{h}^{-1}\right) ; \\
A_{d} & =\text { surface area of biodiscs }\left(\mathrm{m}^{2}\right) ; \\
V_{r} & =\text { effective volume of the reactor }\left(\mathrm{m}^{3}\right) ; \text { and }
\end{aligned}
$$

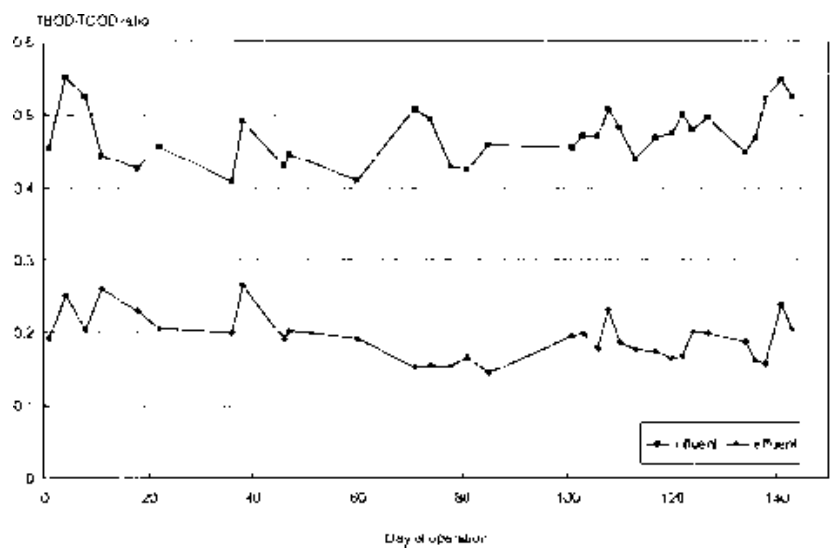

Figure 4-Total BOD and COD ratios for influent and effluent from the RBC.
$C_{\text {in }}$ and $C_{\text {out }}=$ contaminant concentration in the influent and effluent stream of the entire reactor or each stage of the reactor, respectively $(\mathrm{mg} / \mathrm{L})$.

\section{Results and Discussion}

Performance of the RBC reactor during the study can be subdivided into six different phases according to the OLRs applied and disk rotational speed. The results of operating conditions and performance of the RBC reactor are presented in Table 2.

Startup. During startup, the RBC reactor was filled with raw wastewater from a slaughterhouse and inoculated with a seed culture from an activated-sludge unit of a domestic wastewater treatment plant. Feeding was started at an HRT of 3 days. After a week, a thin biofilm was observed on the disks. At this time, feed was switched to the UASB effluent.

Organic Loading Rate. Removal Efficiency. The influence of OLR on process efficiency was studied by applying OLR values between 5 and $18 \mathrm{~g} \mathrm{SBOD} \cdot \mathrm{m}^{-2} \cdot \mathrm{d}^{-1}$ (9 and $34 \mathrm{~g}$ of soluble chemical oxygen demand $\left.[\mathrm{SCOD}] \cdot \mathrm{m}^{-2} \cdot \mathrm{d}^{-1}\right)$. The results in Figure 2 show decreased removal efficiencies with increasing OLRs. The overall removal efficiencies at different OLR values were as follows:

- $\mathrm{SBOD}$ from $85 \pm 4 \%$ to $74 \pm 3 \%$,

- Total biochemical oxygen demand (TBOD) from $75 \pm 4 \%$ to $65 \pm 7 \%$,

- SCOD from $81 \pm 5 \%$ to $69 \pm 7 \%$, and

- TCOD from $76 \pm 4 \%$ to $59 \pm 7 \%$.

Low SBOD and SCOD removal efficiencies in the beginning phases for different rotational speeds (days 1 to 22 and 85 to 114) at OLR values of $17.8 \pm 2.1$ and $11 \pm 2.9$, respectively, resulted in unacceptable effluent quality BOD of 220 to $290 \mathrm{mg} / \mathrm{L}$ ). There was a gradual increase in SBOD removal efficiency at these high OLRs with time, but it did not increase above $50 \%$. Biofilm color in this phase was light gray and the hydrogen sulfide smell was quite noticeable. Reduction of OLR resulted in increased removal efficiencies. The biofilm color changed to brown, the DO concentration reached 0.2 to $0.9 \mathrm{mg} / \mathrm{L}$, and no hydrogen sulfide odor was detectable. 


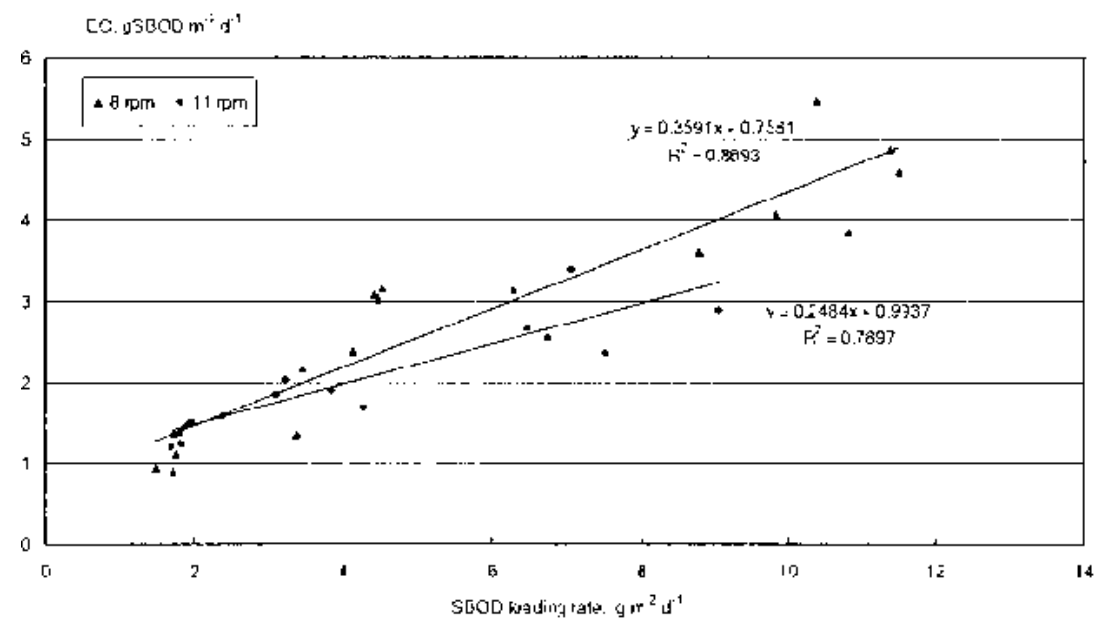

Figure 5-Elimination capacity of the RBC reactor at different OLRs.

Decreased removal efficiencies could have been the result of a combination of heavy biomass growth and oxygen limitations of anaerobically treated wastewater. This, in turn, would have resulted in decreased mass diffusion of substrate and oxygen into the inner layers of active biomass. Available data in the literature confirm the occurrence of these conditions. However, development of anaerobic conditions and foul odor in this study occurred at lower OLR values than those reported in the literature. Previous investigations showed no indication of first-stage overloading problems at loading rates of up to $17.6 \mathrm{~g} \mathrm{SBOD} \cdot \mathrm{m}^{-2} \cdot \mathrm{d}^{-1}$ (Evans, 1985; Surampalli and Baumann, 1997). The main reason for this may be the fact that those studies were conducted on raw industrial or domestic wastewater without any pretreatment. Even though influent DO concentrations in previous studies were as low as $0.5 \mathrm{mg} / \mathrm{L}$, zero DO concentrations were not prevailing most of the time.

The objective of posttreatment of anaerobically treated wastewater is to obtain effluent that meets regulatory requirements for intended uses. Figure 3 shows the results of effluent concentration at different OLRs and two disk speeds ( $8 \mathrm{rpm}$ for days 1 to 85 and $11 \mathrm{rpm}$ for day 85 onward). As illustrated, effluent concentrations meeting local regulatory requirements for agricultural purposes (effluent BOD of $100 \mathrm{mg} / \mathrm{L}$ ) were achieved at an OLR of $5.3 \pm 2.9 \mathrm{~g}$ SBOD $\cdot \mathrm{m}^{-2} \cdot \mathrm{d}^{-1}$, with an SBOD removal efficiency of $85 \pm 3 \%$. Effluent COD values were higher than normal because of the inherent nature of wastewater from the slaughterhouse industry, which contains less biodegradable chemicals used for cleaning facilities and equipment. There was no indication of any improvement based on the changes in rotational speed of the biodisks. Most of the organics were removed in the first stage, with minimal contribution from the remaining stages of the RBC reactor.

A comparison of removal efficiencies in this study with previous investigations indicates lower overall removal efficiencies. The reason for this could be the fact that raw wastewaters were treated in those studies, whereas, in this study, the RBC reactor was located downstream of a UASB system. This was indicated in the $\mathrm{BOD} / \mathrm{COD}$ ratio calculations (Figure 4). Influent and effluent $\mathrm{BOD} / \mathrm{COD}$ ratios for the $\mathrm{RBC}$ were 0.4 to 0.6 and 0.15 to 0.25 , respectively; the influent and effluent $\mathrm{BOD} / \mathrm{COD}$ ratio for raw wastewater is 0.7 to 0.8 (Metcalf \& Eddy, 1991). Results from relatively similar operating conditions are comparable to the findings of this study. For example, for treatment of anaerobically treated domestic wastewater at an OLR range of 6 to $21 \mathrm{~g}$ COD $\cdot \mathrm{m}^{-2} \cdot \mathrm{d}^{-1}$, SCOD and TCOD removal efficiencies of 56 to $73 \%$ and 73 to $83 \%$, respectively, have been reported (Tawfik et al., 2002).

Elimination Capacity. The previous results indicate an adverse effect of increasing OLR on operational indicators such as efficiency. Elimination capacity was used to determine the

Table 3-Elimination capacities at different stages of the RBC reactor.

\begin{tabular}{|c|c|c|c|c|c|}
\hline \multirow[b]{2}{*}{ Disk speed (rpm) } & \multirow[b]{2}{*}{ Parameter } & \multirow[b]{2}{*}{ RBC influent $(\mathrm{mg} / \mathrm{L})^{a}$} & \multicolumn{3}{|c|}{ Elimination capacity $\left(\mathrm{g} \cdot \mathrm{m}^{-2} \cdot \mathrm{d}^{-1}\right)^{a}$} \\
\hline & & & Stage 1 & Stage 3 & Stage 6 \\
\hline 8 & TBOD & $1138 \pm 200$ & $5 \pm 1.1$ & $3.1 \pm 1.4$ & $1.9 \pm 1.5$ \\
\hline 8 & SCOD & $1364 \pm 386$ & $7.6 \pm 2.4$ & $3.4 \pm 1.7$ & $2.8 \pm 3.0$ \\
\hline 8 & TCOD & $2515 \pm 408$ & $14 \pm 1.9$ & $4.9 \pm 2.0$ & $3.1 \pm 2.6$ \\
\hline 11 & SCOD & $874 \pm 20$ & $7.2 \pm 1.3$ & $2.6 \pm 1.5$ & $1.3 \pm 0.7$ \\
\hline 11 & TCOD & $1650 \pm 68$ & $11.7 \pm 2.3$ & $4.8 \pm 2.7$ & $2.3 \pm 1.3$ \\
\hline
\end{tabular}

\footnotetext{
${ }^{a} \pm$ Standard deviation.
} 
influence of increasing OLR on reactor performance. The results shown in Figure 5 for two different disk speeds indicate a linear relationship between OLR and elimination capacity. The linearity of data even at high OLR values indicates that the reactor did not experience limitations regardless of disk rotational speed. However, there seems to be more scatter of the data at higher OLRs.

A summary of the applied OLRs and the associated elimination capacities for different stages of the RBC reactor are shown in Table 3. Average first-stage elimination capacity rates were 4.8 and $3.8 \mathrm{~g} \cdot \mathrm{m}^{-2} \cdot \mathrm{d}^{-1}$ at OLR values of 17.8 and $11 \mathrm{~g}$ SBOD $\cdot \mathrm{m}^{-2} \cdot \mathrm{d}^{-1}$. These values are relatively lower than the almost $50 \%$ removal rate of $17 \mathrm{~g} \mathrm{SBOD} \cdot \mathrm{m}^{-2} \cdot \mathrm{d}^{-1}$ at the OLR value of 38.8 $\mathrm{g}$ SBOD $\cdot \mathrm{m}^{-2} \cdot \mathrm{d}^{-1}$ observed by Surampalli and Baumann (1997) for a combination of municipal and dairy wastewater. As previously suggested, the main reason for this could be the low BOD/COD ratio of UASB effluent and the presence of a higher fraction of less easily biodegradable organic matter. Other parameters that potentially had an influence on the observed elimination capacities include HRT and wastewater temperature. Hydraulic residence times of 13 to 16 hours were higher than the typical contact time f o $\mathrm{r} \quad \mathrm{b}$ i o d e g r a d a t i o $\mathrm{n}$ i $n$ t h e fixed-growth systems. Temperature could also have influenced the low elimination capacity values. However, comparison of the elimination capacity values for the first three phases of the study (temperature $=17.1 \pm 3.1{ }^{\circ} \mathrm{C}$ ) to the last three phases (temperature $=30 \pm 1.7^{\circ} \mathrm{C}$ ) negate this possibility.

Disk Speed. To determine the effect of rotational speed on performance, the system was operated at 8 and $11 \mathrm{rpm}$. A comparison of the results for the two different speeds shows little change in performance based on disk speed. There is a possibility that the peripheral velocity range studied $(0.2$ to $0.28 \mathrm{~m} / \mathrm{s})$ was greater than the optimum and, as a result, no effect was observed. However, Lehman (1983) reported that the upper limit where increased speed results in no improvement is greater than $0.27 \mathrm{~m} / \mathrm{s}$.

\section{Conclusions}

Data presented in this study indicate the feasibility of using RBCs for posttreatment of UASB effluent. Although there was a general trend of decreased removal efficiencies at higher OLRs, there was no indication of reactor elimination capacity even at high OLR values. The results show that a major portion of the removals was realized in the first stage of the reactor. Acceptable effluent quality meeting secondary discharge requirements for agricultural purposes was obtained at an OLR of $5.3 \pm 2.9 \mathrm{~g} \mathrm{SBOD} \cdot \mathrm{m}^{-2} \cdot \mathrm{d}^{-1}$, with an SBOD removal efficiency of $85 \pm 3 \%$.

\section{Acknowledgments}

Authors. Ayoob Torkian and S. J. Hashemian are Associate Professor and Assistant Professor, respectively, at the Sharif University of Technology, Iran; K. Alinejad is with the National Water and Wastewater Company, Iran. Correspondence should be addressed to Ayoob Torkian, Institute of Water \& Energy, Sharif University of Technology, P.O. Box 11365-688, Tehran, Iran; e-mail: torkian@sharif.edu.

Submitted for publication October 5, 2000; revised manuscript submitted August 19, 2002; accepted for publication September 13, 2002.
The deadline to submit Discussions of this paper is May 15, 2003.

\section{References}

American Public Health Association; American Water Works Association; Water Environment Federation (1985) Standard Methods for the Examination of Water and Wastewater, 16th ed.; Washington, D.C.

Andreadakis, A. D. (1987) Design of Multistage Rotating Contactors. J. Environ. Eng. (Reston, Va.), 131, 199.

Banerjee, G. (1997) Hydraulics of Bench-Scale Rotating Biological Contactor. Water Res., 31, 2500.

Blanc, F. C.; Corr, S. H. (1983) Treatment of Beef Slaughtering and Processing Wastewaters Using Rotating Biological Contactors. Proceedings of the 38th Industrial Wastes Conference, Purdue University, West Lafayette, Indiana; Lewis Publishers: Chelsea, Michigan; pp 133-140.

Borghi, M. D.; Palazzzi, E.; Parisi, F.; Ferraiolo, G. (1985) Influence of Process Variables on the Modeling and Design of a Rotating Biological Surface. Water Res., 19, 573.

Evans, F. L. (1985) Consideration of First-Stage Organic Overloading in Rotating Biological Contactor Design. J.-Water Pollut. Control Fed., 57, 1094.

Fang, H. H. P.; Li, Y. Y.; Chui, H. K. (1995) UASB Treatment of Wastewater with Concentrated Mixed VFA. J. Environ. Eng. (Reston, Va.), 121, 153.

Friedman, A. A.; Robbins, L. E.; Woods, R. C. (1979) Effect of Disc Rotational Speed on Biological Contactor Efficiency. J.-Water Pollut. Control Fed., 51, 2678.

Lehman, P. J. (1983) Start-Up and Operating Characteristics of an RBC Facility in a Cold Climate. J.-Water Pollut. Control. Fed., 55, 1233.

Lettinga, G.; Hulshoff Pol, L. W. (1991) UASB-Process Design for Various Types of Wastewaters. Water Sci. Technol., 24 (8), 87.

Lin, S. D.; Schnepper, D. H.; Evans, R. L. (1986) A Close Look at Change of $\mathrm{BOD}_{5}$ in an RBC System. J.-Water Pollut. Control Fed., 58, 757.

Metcalf \& Eddy, Inc. (1991) Wastewater Engineering: Treatment, Disposal and Reuse; McGraw-Hill: New York.

Paolini, A. E. (1986) Effect of Biomass on Oxygen Transfer on RBC System. J.-Water Pollut. Control Fed., 58, 306.

Poon, C. P.; Chin, H. K.; Smith, E. D.; Mikucki, W. J. (1981) Upgrading with RBCs for Ammonia Nitrogen Removal. J.-Water Pollut. Control Fed., 53, 1158.

Saggy, M.; Kott, Y. (1990) Efficiency of RBC in Removing Pathogenic Bacteria from Domestic Sewage. Water Res., 24, 1125.

Strom, P. F.; Chung, J. C. (1985) The Rotating Biological Contactor for Wastewater Treatment. In Advances in Biotechnological Processes 5; Mizrahi, A., Wezel, A. L. V., Eds.; Alan R. Liss, Inc.: New York.

Surampalli, R. Y.; Baumann, E. R. (1997) Role of Supplemental Aeration in Improving Overloaded First-Stage RBC Performance. Water Air Soil Pollut., 98, 1.

Tawfik, A.; Klapwijk, B.; el-Gohary, F.; Lettinga, G. (2002) Treatment of Anaerobically Pre-Treated Domestic Sewage by a Rotating Biological Contactor. Water Res., 36, 147.

Tyagi, R. D.; Tran, F. T.; Chowdhury, A. K. M. M. (1993) A Pilot Study of Biodegradation of Petroleum Refinery Wastewater in a PolyurethaneAttached RBC. Process Biochem., 28, 75.

Ware, A. J.; Pescod, M. B. (1989) Full-Scale Studies with an Anaerobic/ Aerobic RBC Unit Treating Brewery Wastewater. Water Sci. Technol., 21, 197. 